Kamil WĘGLARZ1 ${ }^{1}$, Marcin SIDZINA

Opiekun naukowy: Tomasz KNEFEL ${ }^{3}$

DOI: https://doi.org/10.53052/9788366249837.26

\title{
OCENA MOŻLIWOŚCI STOSOWANIA ŻARÓWEK WYKONANYCH W TECHNOLOGII LED W SAMOCHODOWYCH ŚWIATŁACH MIJANIA
}

\begin{abstract}
Streszczenie: Zgodnie z wymogami homologacyjnymi każdy pojazd samochodowy musi być wyposażony w asymetryczne światła mijania zapewniające kierowcy odpowiednią widoczność w każdych warunkach drogowych. Obecnie tradycyjne reflektory wykorzystujące żarowe oraz ksenonowe źródła światła są wypierane przez technologię wykorzystującą diody LED. Niniejsza publikacja skupi się na analizie zasadności dopuszczenia do eksploatacji na terenie RP zamienników żarówek halogenowych wykonanych w technologii LED.
\end{abstract}

Słowa kluczowe: światła mijania, oświetlenie, bezpieczeństwo, zamienniki LED

\section{EVALUATION OF THE POSSIBILITY OF USING BULBS MADE IN LED TECHNOLOGY IN CAR LIGHT BEAM}

Summary: According to the approval requirements, every car vehicle must be equipped with asymmetrical low beam ensuring the driver adequate visibility in all road conditions. Currently, traditional spotlights using traditional and xenon light sources are being replaced by LED technology. This publication will focus on the analysis of the legitimacy of allowing for use in the territory of the Republic of Poland of replacements for halogen bulbs made in LED technology.

Keywords: low beam, lighting, safety, LED retrofit

\section{Wprowadzenie}

Światła mijania (zwane także krótkimi) - światła silnikowych pojazdów drogowych, używane do oświetlenia drogi $\mathrm{z}$ przodu pojazdu, w założeniach niepowodujące

\footnotetext{
${ }^{1}$ mgr inż., Wydział Budowy Maszyn i Informatyki, Akademia Techniczno-Humanistyczna w Bielsku-Białej, e-mail: kweglarz@2com.pl

${ }^{2}$ mgr inż., Wydział Mechaniki i Budowy Maszyn, Akademia Techniczno-Humanistyczna w Bielsku-Białej, e-mail: msidzina@gmail.com

${ }^{3} \mathrm{dr}$ hab. inż. Prof. ATH, Wydział Budowy Maszyn i Informatyki, Akademia TechnicznoHumanistyczna w Bielsku-Białej, e-mail: knefel@ath.bielsko.pl
} 
oślepienia ani dyskomfortu dla kierowców pojazdów nadjeżdżających z przeciwka oraz dla innych użytkowników drogi. Włączanie tych świateł jest obowiązkowe łącznie lub zamienne ze światłami drogowymi zawsze od zmierzchu do świtu, a także w tunelach, w warunkach pogorszonej przejrzystości powietrza (mgła, silne opady deszczu lub śniegu, zadymienie itp.) oraz podczas holowania. W Polsce włączanie świateł mijania jest obowiązkowe także podczas ruchu pojazdu w dzień, jeżeli nie jest on wyposażony w światła do jazdy dziennej. [1]

\section{Założenia wstępne}

Średni wiek samochodów użytkowanych w Polsce wynosi 13 lat jak wynika z raportu ACEA "Vehicles in use Europe 2018" [2]. Jak powszechnie wiadomo komponenty z których zbudowany jest samochód ulegają z czasem zużyciu. Dotyczy to również reflektorów oraz instalacji elektrycznej. Co za tym idzie spada również ilość światła emitowanego przez światła mijania i pogarsza się oświetlenie drogi przed pojazdem. Wynika to $\mathrm{z}$ jednej strony $\mathrm{z}$ zabrudzania się elementów reflektora, $\mathrm{z}$ drugiej ze spadków napięć występujących w samochodowej instalacji elektrycznej. Druga z tych wad dotyczy jednak tylko oświetlenia halogenowego. W systemie wykorzystującym lampy wyładowcze (ksenonowe) bądź źródła światła wykorzystujące diody LED za stabilizację napięcia i prądu zasilającego element świetlny odpowiada odpowiedni układ elektroniczny pracujący najczęściej w zakresie napięć zasilania od 9 do 16V, więc nieczuły na spadki napięć w instalacji elektrycznej samochodu.

Od wielu lat kierowcy nielegalnie dokonywali modyfikacji oświetlenia w swoich pojazdach. Najpierw z racji dostępności wykorzystywano akcesoryjne zestawy ksenonowe. Ich wadą była, oprócz oślepiania kierowców jadących zna przeciwka również bardzo szybkie degradacja reflektorów nieprzystosowanych do źródeł światła emitujących duże ilości promieniowania UV. Z racji najczęściej dalekowschodniego pochodzenia jakość zestawów pozostawiała wiele do życzenia powodując awarie instalacji elektrycznej, zakłócenia radiowe, a w skrajnych wypadkach nawet pożary.

Od kilku lat zestawy ksenonowe są wypierane przez akcesoryjne zestawy wykorzystujące diody LED. Ich przewagą jest możliwość bardziej precyzyjnego odwzorowania geometrii żarnika żarówki halogenowej, praktycznie brak emisji ciepła i promieniowania UV oraz bardziej kompaktowa budowa pozwalająca bez przeróbek wykorzystywać je w fabrycznych reflektorach. Z upływem lat nastąpiła też daleko idąca poprawa jakości zastosowanych komponentów i wykonania co odbiło się na bezpieczeństwie i niezawodności zestawów.

Niemiecki Federalny Urząd Transportu Samochodowego dopuścił w październiku 2020 pierwsze zestawy akcesoryjnych żarówek LED firmy Osram do legalnego użytkowania na drogach publicznych w wybranych samochodach osobowych:

„Night Breaker LED H7 firmy Osram to pierwsza żarówka LED typu retrofit, która przeszła obszerne procedury testowe TÜV Süd, co czyni ją legalnym zamiennikiem lamp halogenowych $\mathrm{H} 7 \mathrm{w}$ testowanych modelach pojazdów. Potwierdza to niemiecki Federalny Urząd Transportu Samochodowego, udzielając homologacji drogowej. 
Obecnie homologacja obejmuje światła mijania występujące $\mathrm{w}$ wielu popularnych modelach pojazdów zarejestrowanych w Niemczech. Są to popularne modele, takie jak BMW serii 2, Audi A3 i A4 czy Ford Mondeo. Liczba pojazdów jest stale powiększana poprzez ciągłe testy i procedury homologacyjne.” [3]

Niniejsza publikacja skupi się na analizie oświetlania drogi przed pojazdem i porównaniu halogenowych źródeł światła i ich LED-owych odpowiedników oraz wpływowi modyfikacji na bezpieczeństwo jazdy, a także potencjalnym możliwościom ich dopuszczenia do ruchu na drogach publicznych na terenie RP.

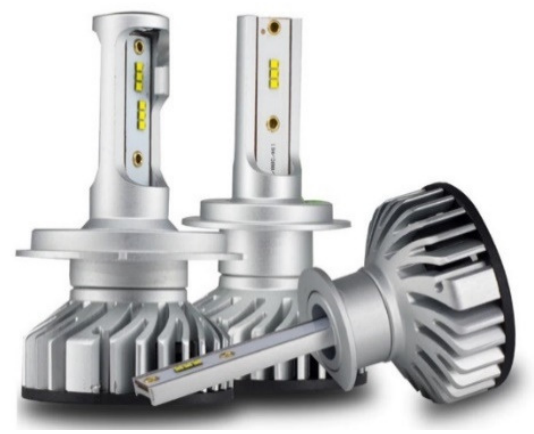

Rysunek 1. Żarówki wykorzystujące diody LED - przykład budowy [4]

\section{Program badań}

Jak wspomniano wcześniej, na potrzeby niniejszej publikacji skupiono się na dwóch aspektach stosowania LED-owych zamienników żarówek halogenowych. Są to:

1. Ilość emitowanego przez reflektor światła.

2. Prawidłowość rozkładu strumienia świetlnego przed pojazdem.

Na potrzeby badań przeprowadzono dwie serie pomiarów po trzy pomiary każda na stanowisku pomiarowym wyposażonym w ekran pomiarowy zgodny z regulaminem 112 Europejskiej Komisji Gospodarczej Organizacji Narodów Zjednoczonych (EKG/ONZ) — „Jednolite przepisy dotyczące homologacji świateł głównych pojazdów silnikowych wyposażonych w żarówki i emitujących asymetryczne światło mijania i/lub światło drogowe." [5] opisane w podpunktach 3.1 - 3.3. W wyniku czego otrzymano dwie serie wyników dla każdego z pomiarów, na podstawie których powstały wykresy obrazujące wpływ ww. czynników na ilość światła przed pojazdem. Metodykę pomiaru oraz ekran pomiarowy opisano we wcześniejszej publikacji [6].

\section{Obiekt badań}

Badaniu poddano dwa reflektory samochodowe:

1. Reflektor samochodu Renault Clio I homologowany do pracy z żarówką H4.

2. Reflektor samochodu Opel Tigra A homologowany do pracy z żarówką H1. 
Do celów pomiarowych zastosowano fabrycznie nowe żarówki renomowanego producenta zasilane napięciem $14,4 \mathrm{~V}$ oraz ich zamienniki w postaci dedykowanych żarówek LED przystosowanych geometrycznie do zastąpienia fabrycznych żarówek halogenowych.

\section{Badania laboratoryjne}

\subsection{Reflektor samochodu Renault Clio I}

Badana lampa samochodu Renault Clio I posiada homologację dla żarówki halogenowej H4, która obsługuje asymetryczne światła mijania i światła drogowe. Na rys. 2 i 3 przedstawiono zmiany natężenia oświetlenia padającego na ekran pomiarowy w zależności od zastosowanej żarówki. Efekt widoczny na rys. 2, 3, 5 i 6 uzyskano fotografując ekran przy tych samych ustawieniach aparatu marki Olympus. Wykorzystano tryb ręcznych ustawień aparatu aby zarówno balans bieli, ustawienia przesłony i czasu ekspozycji pozostały niezmienione. Zdjęcia wykonano w odcieniach szarości. Temperatura barwowa użytych żarówek była zbliżona aby nie wpływała na uzyskany efekt. Uzyskane zdjęcia zostały obrobiono w układzie graficznym zmniejszając ilość kolorów do 10. Dzięki tym zabiegom poszczególne zdjęcia są ze sobą porównywalne.

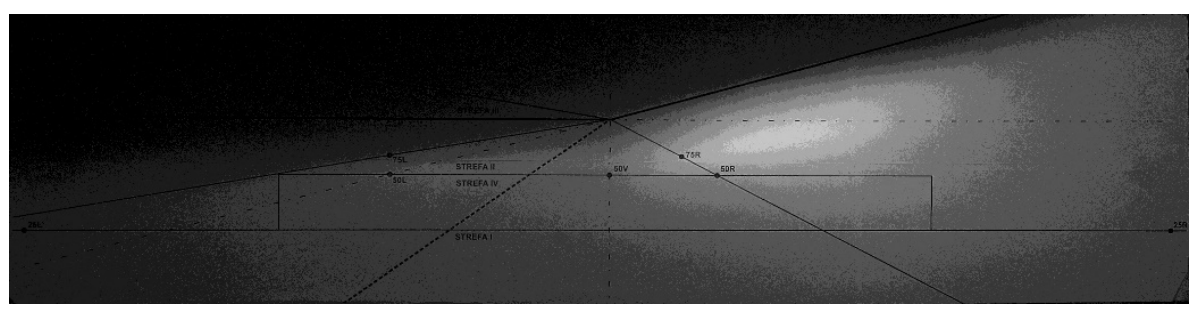

Rysunek 2. Oświetlenie ekranu przy zastosowaniu halogenowej żarówki H4

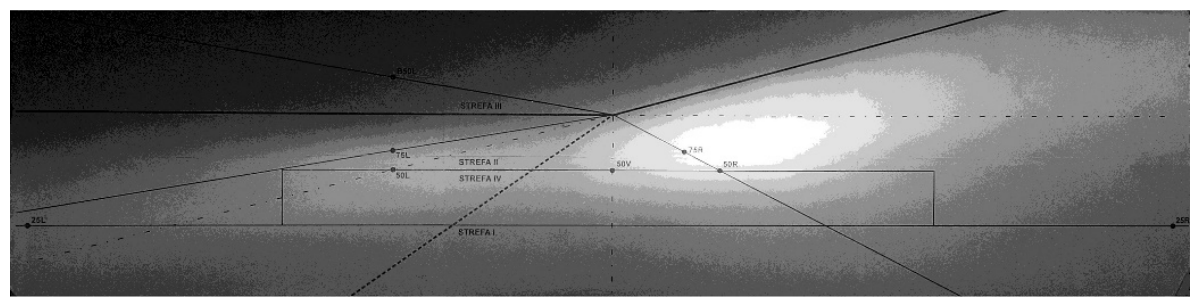

Rysunek 3. Oświetlenie ekranu przy zastosowaniu żarówki H4 LED

Uzyskane wyniki pomiarów dla każdego z ośmiu charakterystycznych punktów pomiarowych zestawiono $\mathrm{w}$ tabeli 1 . Moc poszczególnych żarówek wyliczono korzystając ze zmierzonych wartości napięć zasilających i prądów płynących przez poszczególne żarówki. Powyższe wartości zostały zmierzone podczas testu. 
Tabela 1. Wyniki pomiarów natężenia oświetlenia generowanego przez reflektor samochodu Renault Clio I dla różnych punktów pomiarowych

\begin{tabular}{|c|c|c|c|c|}
\hline L.p. & Punkt pomiarowy & H4 [lx] & LED H4 [1x] & H4 LED $>$ H4 [\%] \\
\hline 1. & $25 \mathrm{~L}$ & 500 & 1000 & 100,0 \\
2. & B50L & 133 & 267 & 100,8 \\
3. & $75 \mathrm{~L}$ & 792 & 1115 & 40,8 \\
4. & $50 \mathrm{~L}$ & 918 & 1723 & 87,7 \\
5. & $50 \mathrm{~V}$ & 1644 & 3818 & 132,2 \\
6. & $75 \mathrm{R}$ & 1962 & 4621 & 135,5 \\
7. & $50 \mathrm{R}$ & 2020 & 4521 & 123,8 \\
8. & $25 \mathrm{R}$ & 957 & 2422 & 153,1 \\
\hline
\end{tabular}

Graficzne zestawienie wyników przedstawiono na rys. 4 i 7. Widoczna jest znacząca różnica pomiędzy natężeniem oświetlenia zarejestrowanego w poszczególnych punktach pomiarowych w zależności od zastosowanej żarówki.

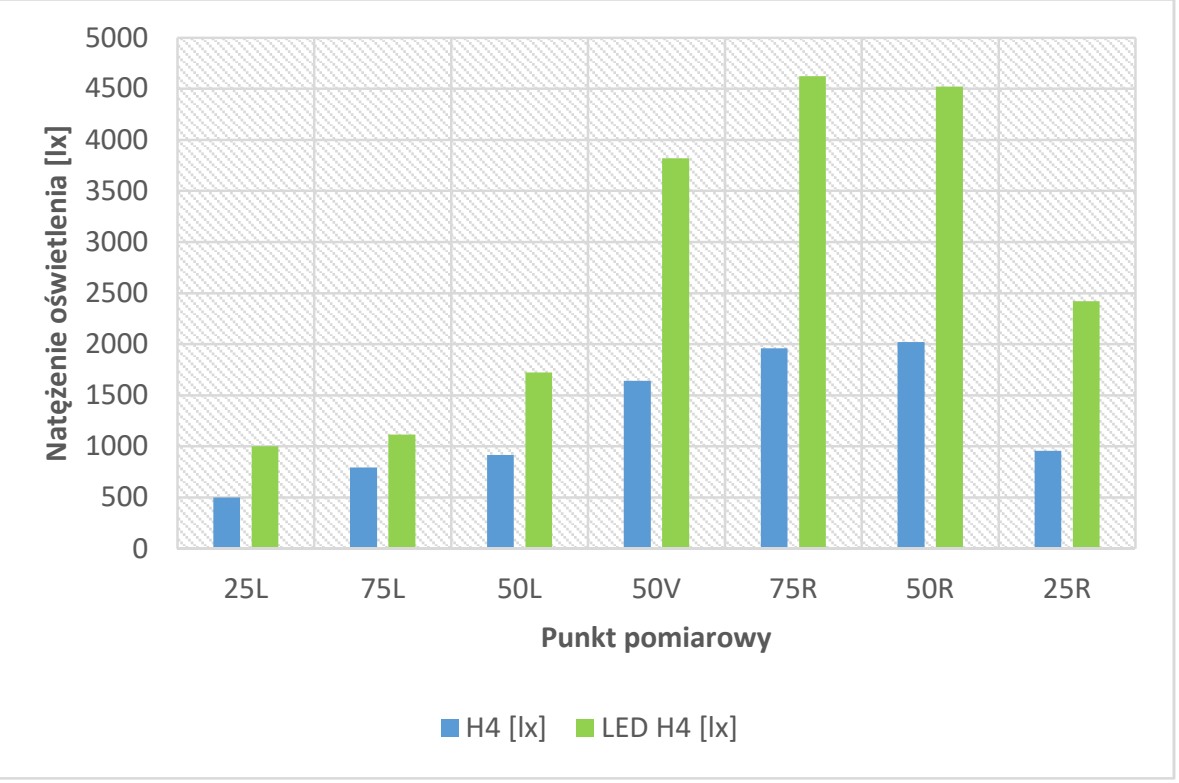

Rysunek 4. Zestawienie uzyskanych wyników pomiarów dla żarówek H4

\subsection{Reflektor samochodu Opel Tigra A}

Lampa samochodu Opel Tigra A posiada homologację dla żarówki halogenowej H1, która obsługuje asymetryczne światła mijania. Na rys. 5 i 6 przedstawiono zmiany 
natężenia oświetlenia padającego na ekran pomiarowy w zależności od zastosowanej żarówki.

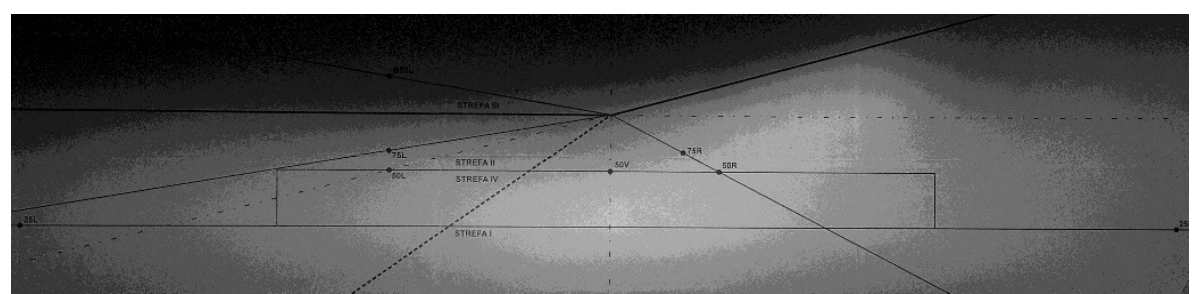

Rysunek 5. Oświetlenie ekranu przy zastosowaniu halogenowej żarówki H1

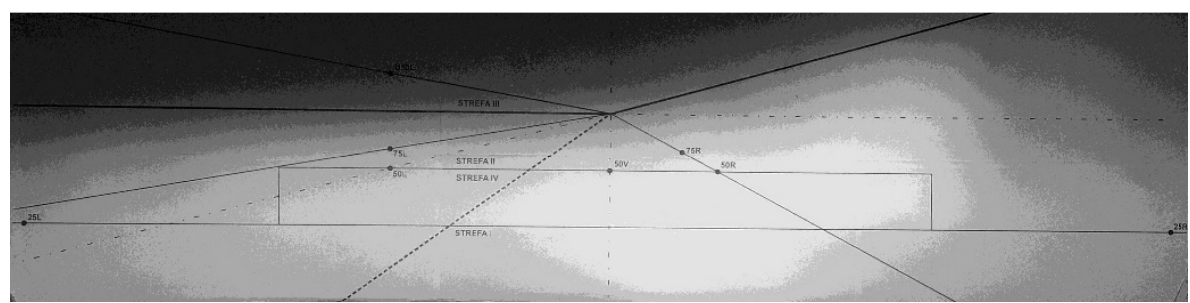

Rysunek 6. Oświetlenie ekranu przy zastosowaniu żarówki H1 LED

Uzyskane wyniki pomiarów dla każdego z ośmiu charakterystycznych punktów pomiarowych zestawiono $w$ tabeli 2 oraz na rys. 7 .

Tabela 2. Wyniki pomiarów natężenia oświetlenia generowanego przez reflektor samochodu Opel Tigra A dla różnych punktów pomiarowych

\begin{tabular}{|c|c|c|c|c|}
\hline L.p. & Punkt pomiarowy & H1 [lx] & LED H1 [lx] & H1 LED/H1 [\%] \\
\hline 1. & $25 \mathrm{~L}$ & 467 & 1050 & 124,8 \\
1. & B50L & 185 & 274 & 48,1 \\
2. & $75 \mathrm{~L}$ & 642 & 1127 & 75,5 \\
3. & $50 \mathrm{~L}$ & 1111 & 1834 & 65,1 \\
4. & $50 \mathrm{~V}$ & 1538 & 3729 & 142,5 \\
5. & $75 \mathrm{R}$ & 1242 & 3175 & 155,6 \\
6. & $50 \mathrm{R}$ & 2008 & 4920 & 145,0 \\
7. & $25 \mathrm{R}$ & 984 & 2391 & 143,0 \\
\hline
\end{tabular}




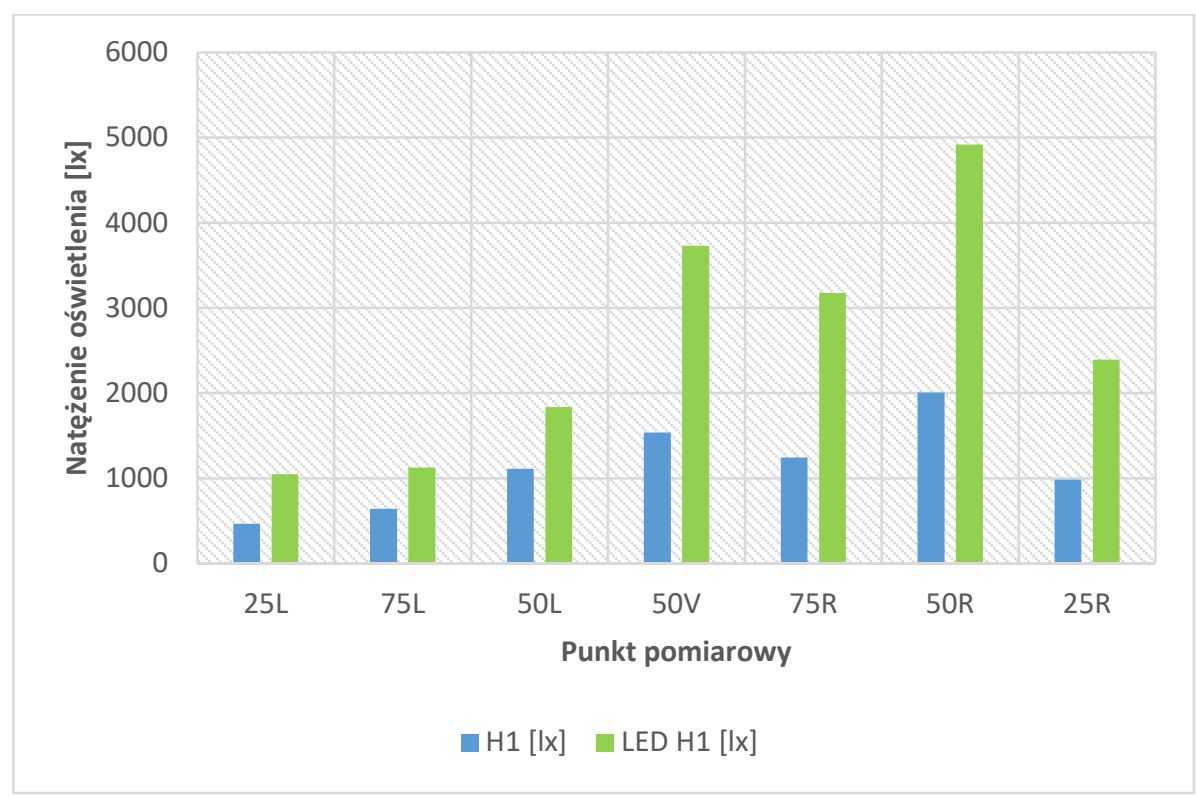

Rysunek 7. Zestawienie uzyskanych wyników pomiarów dla żarówek H1

\section{Podsumowanie wyników}

Z uzyskanych wyników jasno widać, że w przypadku zastosowania żarówki wykorzystującej diody LED zamiast tradycyjnego żarnika uzyskuje się większe wartości natężenia oświetlenia, wykorzystywane do oświetlenia drogi przed pojazdem. Pomimo zastosowania diod emitujących zbliżoną i nieprzekraczającą normy dla tradycyjnej żarówki ilość luxów uzyskuje się o wiele lepsze oświetlenie ekranu pomiarowego. Wynika to m.in. z budowy żarówki LED-owej oraz konstrukcji reflektora. Umieszczenie diod po obu stronach cienkiego kształtownika i skierowanie ich światła „na boki” gwarantuje optymalne wykorzystanie konstrukcji odbłyśnika reflektora. Odbłyśnik „korzysta” bowiem w przeważającej większości ze światła emitowanego na boki w reflektorze wykorzystującym żarówkę H1 i ze światła emitowanego na boki i ku górze $w$ reflektorze $\mathrm{z}$ żarówką $\mathrm{H} 4$. Ze względu na konstrukcję żarówki LED mają miejsce o wiele mniejsze straty strumienia świetlnego, dzięki jego ukierunkowaniu wynikającemu $\mathrm{z}$ budowy diod LED. Kwestią wymagającą dokładniejszych pomiarów jest wzrost o ponad $100 \%$ natężenia światła padającego na punkt B50L, który symbolizuje oślepienie kierowców jadących z przeciwka. Pomimo emitowania zbliżonego strumienia świetlnego przez żarówkę wykorzystującą diody LED koniecznym jest bardzo dokładne ustawienie reflektorów, ponieważ przy złym ustawieniu istnieje o wiele większe prawdopodobieństwo oślepiania innych kierowców. Mimo tego zastosowanie żarówki LED wykazało, że rozkład plamy świetlnej pozostał prawidłowy i zapewniał kierowcy komfortowe warunki jazdy. Dodatkowym atutem jest ponad 50\% redukcja zużycia energii elektrycznej co pokazane zostało w tabelach pomiarowych, a także możliwość 
wyboru najbardziej odpowiadającej kierowcy temperatury barwowej światła w zakresie dopuszczalnego zakresu dla światła białego.

\section{Wnioski}

Przeprowadzone pomiary wykazały, że w przypadku badanych żarówek mamy do czynienia ze $110 \%$ wzrostem ilości światła padającego na drogę przed pojazdem w przypadku żarówki LED w wersji H4 i ponad 120\% w przypadku żarówki H1. Pomimo, że żarówki LED emitują podobne wartości strumienia światła co ich halogenowe odpowiedniki dzięki lepszemu jego ukierunkowaniu mamy do czynienia z lepszym wykorzystaniem potencjału reflektorów. Z przeprowadzonych badań jasno wynika bardzo duży potencjał zastosowania oświetlenia LED w starszych samochodach w kontekście poprawy bezpieczeństwa i komfortu jazdy. Przedmiotowa publikacja skupia się jedynie na wynikach badań dwóch reflektorów starszej konstrukcji. Niestety ze względu na specyfikę konkretnych konstrukcji należy wzorem Niemiec przebadać każdy z popularnych modeli pod kątem możliwości zastosowania żarówek LED danego producenta, a także przygotować, wzorem istniejących wymagań dla żarówek halogenowych przygotować analogiczną specyfikację techniczną, którą muszą spełniać żarówki wykorzystujące diody LED. Precedens z którym mamy do czynienia na rynku niemieckim otwiera jednak drogę do ujednolicenia legislacji w innych krajach Unii Europejskiej w tym w Polsce. Zastosowanie oświetlenia LED pozwala zwiększyć bezpieczeństwo i komfort jazdy kierowcy, niosąc za sobą inne benefity w postaci nowocześniejszego wyglądu pojazdu, oszczędności energii elektrycznej i zwiększonej żywotności diod LED względem żarówek halogenowych.

\section{LITERATURA}

1. DZIUBIŃSKI M., OCIOSZYŃSKI J., WALUSIAK S.: Elektrotechnika i Elektronika w samochodach. Wydawnictwa uczelniane Politechniki Lubelskiej, Lublin $1999 \mathrm{r}$.

2. ACEA Report "Vehicles in use Europe 2018"

3. Oficjalna informacja prasowa firmy Osram, Monachium, $2020 \mathrm{r}$.

4. Strona internetowa: https://www.philips.pl/

5. Regulamin 112 Europejskiej Komisji Gospodarczej Organizacji Narodów Zjednoczonych (EKG/ONZ) — „Jednolite przepisy dotyczące homologacji świateł głównych pojazdów silnikowych wyposażonych w żarówki i emitujących asymetryczne światło mijania i/lub światło drogowe." Dziennik urzędowy UE, $2005 \mathrm{r}$.

6. WĘGLARZ K.:, Problem eksploatacyjnego zużycia elementów układu świateł mijania w samochodach osobowych i jego wpływ na komfort jazdy i bezpieczeństwo, Wydawnictwo pokonferencyjne „Inżynier XXI wieku”, Bielsko-Biała 2019 r. 